\title{
REMEDIAL INVESTIGATION OF LARGE SCALE KARSTIC FLOW CONDUITS WITH BRINE-ENHANCED RESISTIVITY IMAGING AND DOWNHOLE COLLOIDAL BORESCOPE METHODS
}

\author{
James L. Lolcama
}

KCF Groundwater, Inc., 4916 Woodbox Lane, Mechanicsburg, PA, 17055, USA, jll@kcfgroundwater.com

\begin{abstract}
Locating conduit-type permeability in karstified limestone and dolomite and measurement of flow velocity and flow direction are key requirements for remediation of groundwater contamination, and sealing of massive inflows to pits, quarries, and underground mines. The massive rates of water inflow to a mine can cause catastrophic flooding in days to weeks, requiring a rapid reconnaissance method that can locate deep karstic permeability in a shortened timeframe as compared to traditional geophysical and drilling methods. Off-site migration of groundwater contaminants can occur by conduit flow in days to weeks as compared to much longer timeframes for diffuse flow permeability, and remediation often requires rapid remedial planning, and strategic grouting of selected conduits to eliminate the major transport pathways.
\end{abstract}

Resistivity profiling was used in conjunction with salt brine enhancement of the conduit flow to locate and image deep-lying karst flow conduit features using the Advanced Geosciences, Inc. (AGI) SuperSting R8 earth resistivity geophysical equipment. The equipment consists of the meter, external power supply, and 112 electrodes at $3 \mathrm{~m}$ spacings, for a surveyed length of $333 \mathrm{~m}$ $(1,092 \mathrm{ft})$. Ambient resistivity conditions were measured throughout the surveyed area, and the average depth to karst bedrock was determined. Constant-rate injection of saturated $\mathrm{NaCl}$ brine solution into the flow conduit was commenced after the background survey was completed, and the conductivity of the conduit water was increased by roughly 10 times background. A second resistivity survey was conducted in which the resistivity readings above the top of bedrock were not collected to reduce the duration of data collection, and to reduce the brine volume requirement. The volume of saturated brine that is required is typically about $57,000 \mathrm{~L}$ ( 15,000 gallons) at a continuous pumping rate of $757 \mathrm{~L} / \mathrm{min}(200 \mathrm{GPM})$. The 2-D models of subsurface resistivity from the prebrine, and brine-enhanced surveys are subtracted to produce a conductive anomaly map. For a project site in Hagerstown, Washington County, Maryland, a 2-D anomaly of roughly $-500 \mathrm{Ohm}-\mathrm{m}$, with a cross-sectional area of about $1,860 \mathrm{~m}^{2}\left(20,000 \mathrm{ft}^{2}\right)$, was detected. The total survey area was roughly $12 \mathrm{X}$ this size. The conductive anomaly was drilled with multiple boreholes, and conduit flow to a nearby mine was identified within weeks. The brine-enhanced 2-D electrical resistivity survey is believed to be the first application of its kind at this scale. The preliminary methodology and initial results from two case studies have been presented in Lolcama and Stuby (2015).

The colloidal borescope instrumentation by AquaVision utilizes natural colloidal particles which are suspended in the conduit flow past a video camera to determine groundwater flow velocity and direction. The system is capable of analyzing flow measurements every 4 seconds, and produces a very large dataset of several thousand particles tracked during an hour long test. The borescope can measure groundwater velocities from near zero up to $1.6 \mathrm{~m} / \mathrm{min}$ (5 fpm). Testing of deep conduit flow that was encountered by drill holes was completed at a site in south-central Pennsylvania, which is different from the Hagerstown, MD site. Testing showed that the average direction of horizontal flow through the karst conduit features lies at about azimuth 64 degrees, or towards the east-north-east, with an average groundwater velocity of roughly $0.002 \mathrm{~m} / \mathrm{s}(0.3 \mathrm{fpm})$, with occasional spikes in velocity to $0.01 \mathrm{~m} / \mathrm{s}(1.7 \mathrm{fpm})$. The velocity is similar in magnitude to point dilution testing results for the same karstic flow field. The results were instrumental in achieving a better understanding of the locations of conduit flow features beneath the site, and the flow velocities and directions which were needed for remedial planning purposes.

\section{Introduction and Background}

Both sites are located in the Mid-Atlantic State region where the karst is typical of a mountainous setting, with carbonate bedrock encountered within regional scale geologic structures, such as plunging, tightly folded 
synclines and anticlines and other forms of deformation. The preferential groundwater dissolution of limestone leaves terra rossa clay fill, sand, and rock debris in the karst voids and caverns. The interconnection of the karst voids has formed regional-scale karst channels in the bedrock, and we have encountered these pathways

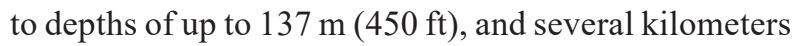
in length (Bruce et al., 2001).

Seepage and groundwater infiltration that results when mines, tunnels, and other deep excavations intercept a transmissive karst conduit can result in headward scouring of terra rossa clay, silt and other residuum filling the feature, effectively enhancing the transmissivity of the feature. Groundwater flow along these scoured conduits can increase rapidly and overwhelm dewatering pumps, and in extreme cases can cause catastrophic flooding of below grade excavations.

When a geotechnical or environmental crisis occurs in karst geology, where the groundwater flow is predominantly through deep-lying and isolated massive flow conduit features, remedial location of the flow features within very tight timeframes can seem nearly impossible to the individuals responsible for identifying a solution. Engulfed in the crisis, the owners of these properties all too often attempt a repair which does not suit the ground conditions, because they have been unable to complete a meaningful investigation to understand the problem in the time available. If too large of an area is targeted for remedial treatment, the crisis can turn into a seminal event if not turned around, by triggering the expenditures of huge sums of money without the likelihood of success. Paradoxically, crisis management guidance for these types of geotechnical problems (Bruce, 2004) teaches us that understanding the hydrogeologic and geotechnical scope and details of the problem is the key to selecting the correct repair strategy, and achieving a successful outcome.

This paper presents two different remedial case studies in the rapid, reconnaissance, location and characterization of large scale, karst conduit-type groundwater flow through bedrock using a novel brineenhanced electrical resistivity surveying (BEERS) method, and a downhole colloidal borescope (CB) method.

\section{Methodology Colloidal Borescope Method}

The colloidal borescope was first introduced to the commercial market by AquaVision in 2000 for direct, borehole measurement of laminar and turbulent groundwater flow velocity and average flow direction, using quantitative video particle tracking methods. The application described here is a delineation of contaminant transport directions and velocities in a complex karst aquifer, in which conduit flow pathways are embedded within a fractured carbonate aquifer. The dissolved phase contaminant mass in the aquifer is being removed by pump and treat methods, to depths of up to 250 feet. Our conceptual model is that contaminant mass is transported rapidly through an anastomosing network of conduits, and more slowly through the fracture networks. The purpose of the testing is to determine if the contamination is evading the capture wells by migration within the nested flow conduit features.

A portable borescope instrument system package includes the borescope and controller, communication/ data cable and reel, and field computer with controller software. From Wilson et al. (2001), the natural colloidal particles which are scoured from clay-fill in karst become suspended in the groundwater flow which flows across the field of view of the video camera/borescope, which is suspended in the borehole and stationary. Particles are digitized and tracked by computer for speed and direction of movement. Only horizontal particle movement is considered, as particles with a substantial vertical movement tend to become unfocussed over time, and the tracking software eliminates their trajectories. An onboard compass, or flux-gate magnetometer, is utilized to determine particle directions. After AquaVision (2000), the system is capable of analyzing flow measurements every 4 seconds, resulting in a large data base of several thousand particles tracked during a typical one to two hour long testing period, adding to the accuracy and reliability of the results. The borescope is capable of measuring velocities up to $1.5 \mathrm{~m}(5 \mathrm{ft})$ per minute, which is applicable to turbulent flow. The provided AquaLITE software creates a data file with colloid speed and horizontal direction, number of particles tracked, and the date and time of a measurement. A statistical summary is created with average speed and direction, and data variability about the arithmetic mean statistic. Roughly 1 megabyte of data is collected per one to two hour test period; a typical test measures several thousand particles. 
RockWorks software (Rockware, 2012) was used to create a circular histogram plot for each test location in the borehole. Each of the petals in the circular histogram is a 5 degree increment in the flow direction of the karst groundwater. An example plot of the directional data, with test statistics, for a test containing 2,854 particles is shown in Figure 1.

\section{Example of CB Implementation and Data Interpretation}

For the application site described above, where karstified limestone and dolomite bedrock underlie an industrial site in south-central Pennsylvania, optical televiewer logging was completed in several boreholes, and the example provided is from a test interval in a deep borehole that penetrated a zone of karst from roughly $61 \mathrm{~m}(201 \mathrm{ft})$ to $67 \mathrm{~m}(218 \mathrm{ft})$ depth below grade. The borehole log showed an open karst void from $65 \mathrm{~m}$ (213 ft) to $67 \mathrm{~m}$ (218 feet). The borehole was cased and sealed from grade to $61 \mathrm{~m}(200 \mathrm{ft})$ depth. No other voids were exposed in the borehole during testing. Testing was performed in an open hole section of the borehole below $61 \mathrm{~m}(200 \mathrm{ft})$. Vertical flow was minimal. After testing for roughly one hour, the average horizontal flow direction through the borehole was azimuth 43 degrees, or north-east, with a 5 degree envelope about the average direction comprising the 95\% confidence interval. The other directions shown are most likely caused by a slight swirling action to the groundwater in the borehole immediately after borescope insertion. The average groundwater velocity is $0.021 \mathrm{~m} / \mathrm{min}(0.07 \mathrm{fpm})$, and the median velocity is $0.015 \mathrm{~m} / \mathrm{min}(0.05 \mathrm{fpm})$, with occasional particle velocities up to $0.52 \mathrm{~m} / \mathrm{min}$ (1.7 fpm). By comparison, point dilution testing at this depth showed groundwater velocity of $0.39 \mathrm{~m} / \mathrm{min}(1.28 \mathrm{fpm})$. The results demonstrated a potential for deep-lying turbulent flow beneath the site. Future refinement of the field methods for $\mathrm{CB}$ will focus on minimizing the slight swirling effects caused by the insertion of the probe.

\section{Requirements}

A minimum set of requirements are provided as a guide:

1. 4 inch or larger open borehole access to the flow conduit feature of interest. Do not perform the testing through a well screen, either filtered or not filtered.
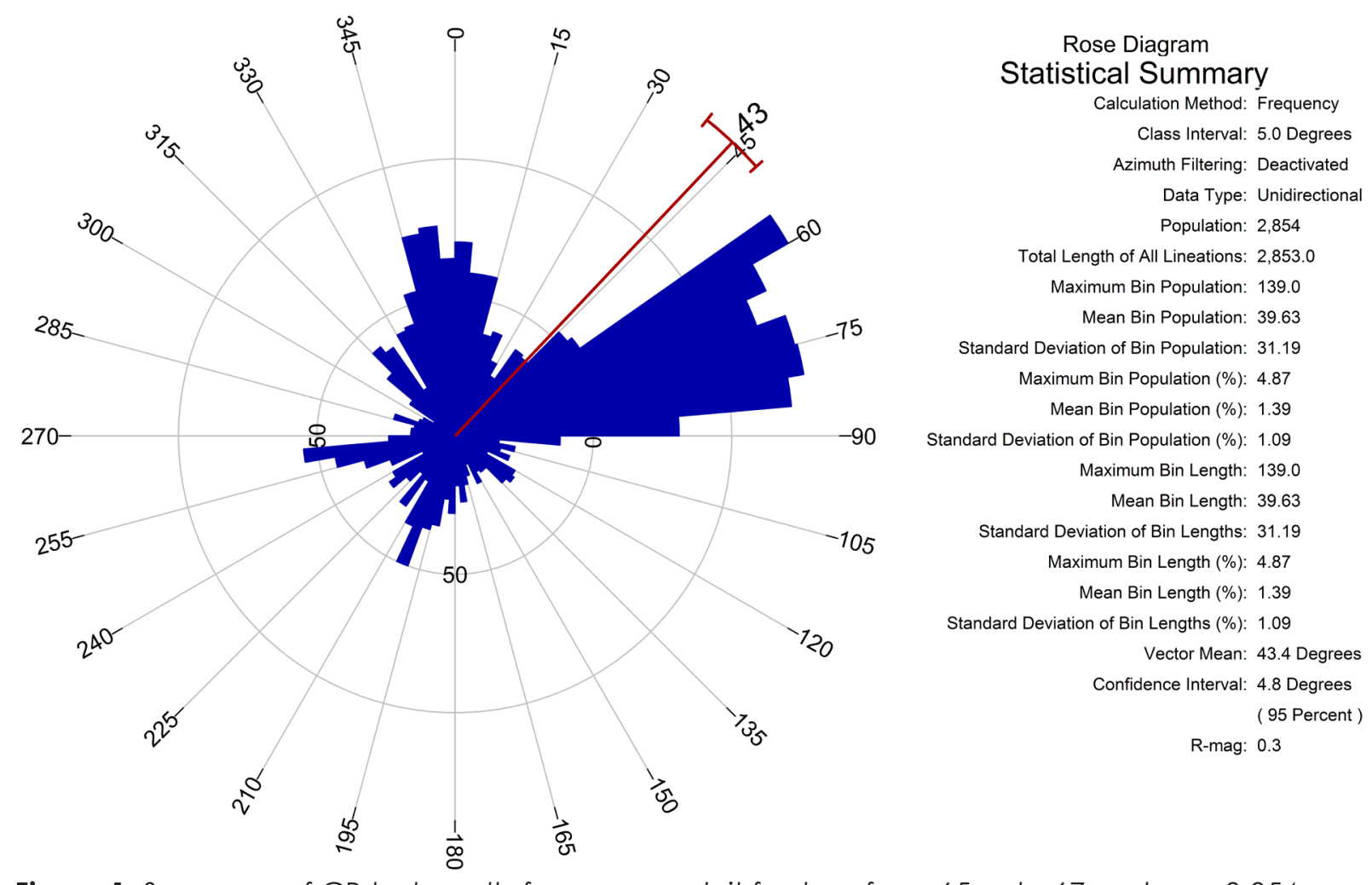

Figure 1. Summary of CB test results for one conduit feature from $65 \mathrm{~m}$ to $67 \mathrm{~m}$ deep. 2,854 colloidal particles tracked during a roughly one hour test period. 
2. Perform the borescope work in natural flow conditions undisturbed by, for example, aggressive pumping nearby.

3. If equipment allows, measure the groundwater turbidity of the test zone, and compare with other test locations. Anomalous turbidity can cause random scattering effects, thus reducing the quality of the data.

4. Allow a period of time to pass after setting the borescope at the required depth before commencing logging, to reduce eddy effects in the colloid movements.

5. Make the necessary equipment adjustments to minimize edge effects/video interferences prior to the start of logging, and during logging. This is not a 'set it and forget it' technology.

6. Set a goal of several thousand particles tracked, if time allows, for best direction and velocity results.

\section{BEERS Method}

After Nettles et al. (2007), at-grade electrical resistivity technology (ER) provides two-dimensional information on the electrical properties of subsurface materials, which can be used to infer geologic structures such as top of rock and overburden thickness, presence of fractures, and the presence of voids and cavernous formations. However, the turbulent flowing water of a karst flow conduit cannot be differentiated from either the stagnant water in storage in an isolated void or cavern, or the diffuse flow of a fractured bedrock system. This differentiation of turbulent flow from diffuse and laminar flow is required for remedial planning purposes. AquaTrack $^{\mathrm{TM}}$ technology by Willowstick (2006) is useful for locating water-seepage zones through the subsurface, such as might be afflicting a dam structure, however the method cannot differentiate between seepage and turbulent flow. The heat pulse flow meter (Kerfoot, 1988) is a direct measurement for flow velocity for borehole use which is limited to much less than 1 foot per minute, which is laminar to sub-turbulent flow. Point dilution testing methods are limited in not being able to discern the direction of the tracer movement.

The BEERS method incorporates saturated salt brine injection into the groundwater recharge through the geophysical test zone, enabling the method to differentiate the large, turbulent-type flow through bedrock from otherwise conductive karstic features such as clay or water filled voids and caverns with laminar flow, to depths of up to $76 \mathrm{~m}(250 \mathrm{ft})$. The new method significantly decreases the time required to locate conduit flow, enabling a more focused and successful remedial treatment.

The brine-enhanced electrical resistivity survey is a time-lapse geophysical method first attempted by the authors in 2007 at a mine site in West Virginia that was taking on water from an adjacent river at large flow rates. Water was flowing through a known entry point in the river bottom and emerging in the quarry bottom as confirmed by a saline tracer test. An electrical resistivity profile could easily be acquired between the entry point and quarry. A background measurement was initially made to assess the steady-state subsurface conditions along the profile. The approach of the technique was to actively change subsurface electrical properties by injection of a large volume of saline solution (brine) through the entry point, and measuring the subsurface again while the saline solution was below the electrode array. Differences between the background measurement and the post-injection measurement were expected to be caused only by the brine which was travelling through the conduit between the river and quarry. In this way the horizontal location and depth of the conduit were determined.

The technique was subsequently applied twice at another quarry in Maryland with similar conditions. The first use was to identify the subsurface location of the conduit as in the WV quarry. The second use followed a major program of grouting activity, which had partially grouted closed a deep flow conduit network, and the owner was attempting to understand the extent of the remaining area to be grouted. These case studies are described in Lolcama and Stuby (2015).

Resistivity profiles were acquired using the SuperSting R8 Earth Resistivity Meter by Advanced Geosciences, Inc. (www.agiusa.com/supersting). In this BEERS survey case study, the SuperSting controlled a set of 112 electrodes spaced between 3.4 and $5.2 \mathrm{~m}$ (11 and $17 \mathrm{ft}$ ), depending on available space for the array. This resulted in arrays of lengths from 372 to $575 \mathrm{~m}$ (1221 to $1887 \mathrm{ft}$ ), which provided subsurface resistivity results to approximately $76 \mathrm{~m}$ and $122 \mathrm{~m}(250 \mathrm{ft}$ and $400 \mathrm{ft})$ respectively. 


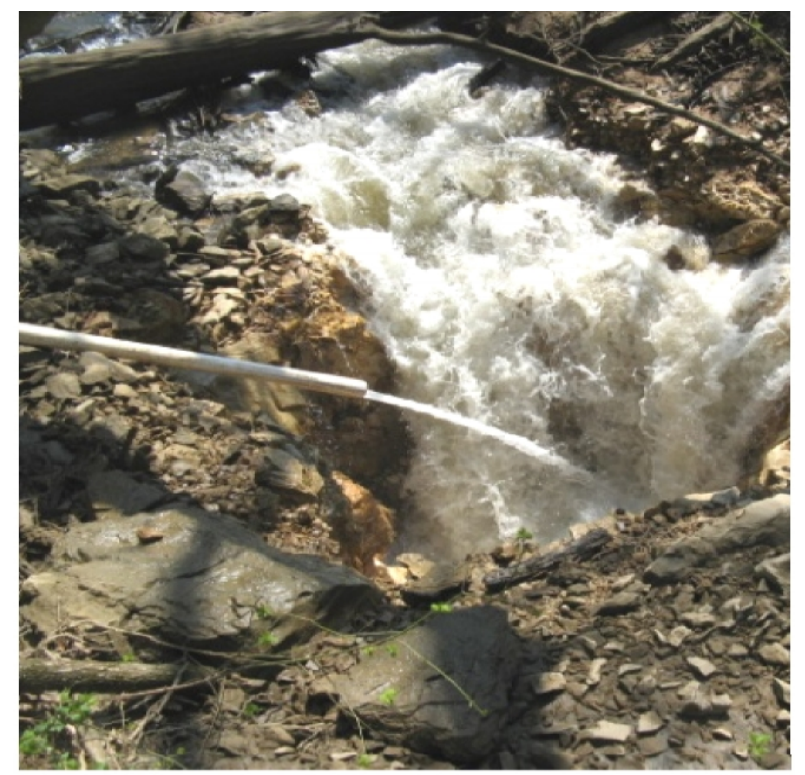

Figure 2. Brine solution addition to the river water recharge to the subsurface conduit.

The brine itself was a saturated solution of $\mathrm{NaCl}$, and volumes of up to $56,781 \mathrm{~L}(15,000 \mathrm{gal})$ were injected over a period of 60 to 90 minutes (Figure 2). The travel time of subsurface water through the conduit was known from tracer testing, so that the approximate time of arrival of the brine below the electrical resistivity array could be calculated, and resistivity measurements did not begin until this time in each case.

A detailed discussion of the geophysical test design, field data collection methods and processing of the data is provided in Lolcama and Stuby (2015).
The resistivity values for the test area with brine-injection were subtracted from the corresponding values in the background (no brine) model. In this way the drop in subsurface electrical properties caused by the presence of the brine appeared as negative values, and these negative values represent the location of the subsurface conduit connecting the river to the mine.

The negative anomaly observed on the second survey at the Hagerstown, Maryland mine site was the most clear and intense of those observed on the three surveys. The survey was completed across a deep faulted zone which interconnected a nearby river and quarry, and the river provided recharge to the fault zone. The left-half of the surveyed zone had been grout-sealed with cement-based grout, whereas the right-half has yet to be grouted. The anomaly is shown as "A-A" on Figure 3, and demarcates the area of conduit flow that remains after grouting. Note that positive anomalies are also observed on either side of the central negative anomaly. These are almost certainly artifacts of the iterative inverse modeling algorithm. The anomaly was confirmed to be the flooding flow conduit by drilling several boreholes through the anomaly and tracing the karstic flow connection to the nearby mining operation using the boreholes for tracer injection.

\section{Requirements}

A set of requirements are provided as a guide:

1. A naturally-occurring inlet point to the conduit would normally be located, such as a sinkhole throat in an adjacent river, or upstream of the dam

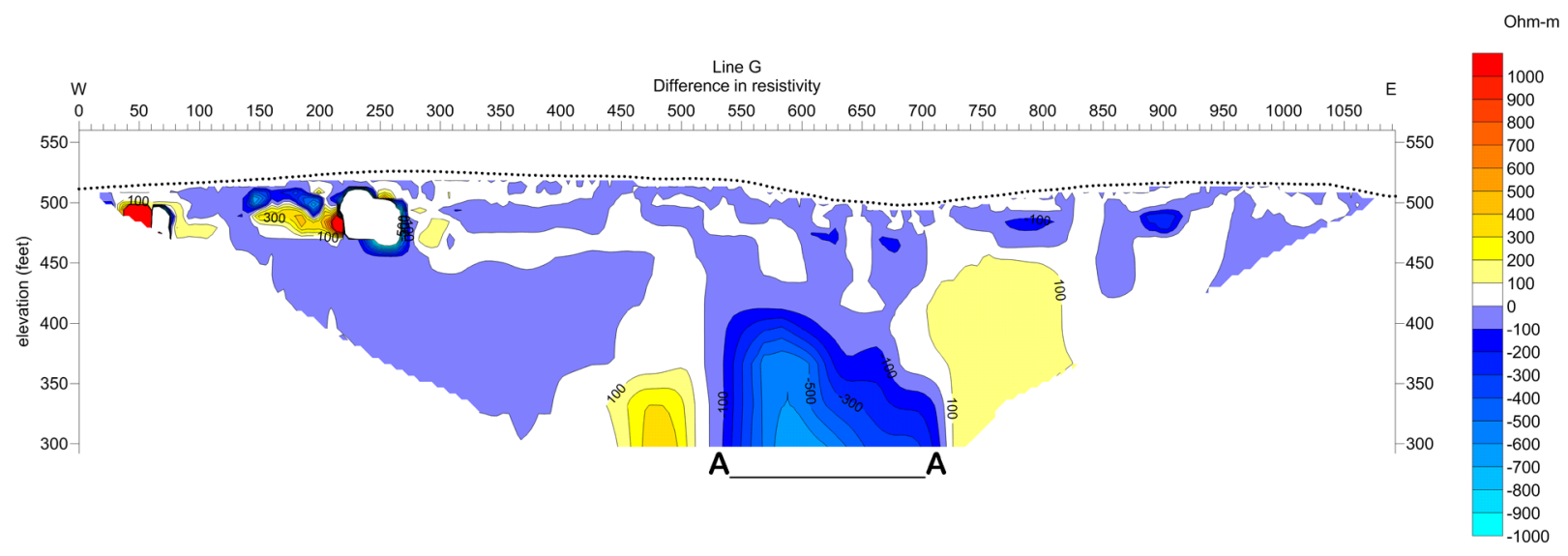

Figure 3. Resistivity profile showing differences in modeled subsurface resistivity between background and brine-injection models. The dotted line is the ground surface, and distances are in feet. " $A$ " indicates the significant drop in resistivity of over 500 Ohm-m presumed to be caused by the brine, and which indicates the location of the flow conduit. Anomalies (positive or negative) above $450 \mathrm{ft}$ elevation were above the river level and could not represent flow conduits. 
structure. Otherwise, an injection borehole or two would be installed through the top of the conduit.

2. The rough strike of the flow conduit feature through the bedrock should be determined to guide the investigation.

3. The average flow velocity inside of the conduit should be determined by quantitative tracing.

4. Environmental State Agency-permission to inject salt brine may be required, and their requirements for salt-monitoring in local waterways must be adhered to, including establishing background, and demonstrating no impact during injection and for several days post-injection.

5. Locate allowable space to place a $300 \mathrm{~m}+(1,000 \mathrm{ft}$ + ) resistivity profile between the inlet and quarry, oriented perpendicular to the flow direction, and preferably in a straight line (although some curvature is allowable).

6. Stage sufficient brine at the project site to inject into the flow conduit over a period of roughly one hour with a pumping rate of at least $379 \mathrm{~L} / \mathrm{min}$ (100 gpm).

\section{Conclusions and Perspectives}

The hydrogeology of the SE Pennsylvania project site is highly complex with large scale karstic flow conduits nested within a fractured carbonate aquifer. The contaminant transport directions and fast velocities of the conduit features are uniquely different as compared to the fractured bedrock matrix with diffusion-controlled migration. Earlier adoption of the colloidal borescope could have characterized the conduit flow for inclusion in the site hydrogeologic model.

The West Virginia mine site location discussed above, was the location of the largest multi-material grout curtain to halt a major inflow through karst bedrock in North America, completed during 1997 and 1999 (Bruce et al., 2001). The reconnaissance exploration program to locate the flow pathway, while successful in the end at centering the grout curtain on the main body of the conduit flow, required over 7,620 m (25,000 linear $\mathrm{ft}$ ) of 2-D resistivity work through densely wooded terrain, and drilling of roughly 60 deep test borings to $76 \mathrm{~m}(250 \mathrm{ft})$. Access roads had to be cut through the dense brush for geophysical surveying, and for the drilling equipment. Several hundred additional boreholes up to $107 \mathrm{~m}(350 \mathrm{ft})$ deep were drilled to plumb the karst bedrock to accept grout, with each borehole being tested for evidence of conduit flow. The conductive anomalies in the bedrock that were targeted for drilling without knowledge of flow velocity, were water and clay-filled karstic voids. With the highly karstified nature of the dolomite bedrock, due largely to structural deformation and breakage of the rock, very few of the many karstic voids were interconnected. The main body of the flow conduit was restricted to a relatively small cross-sectional area, which eventually was distinguished from static groundwater in storage by water temperature logging of the boreholes. Had the brine-enhancement method been available at the time, countless hours would likely have been saved by targeting the active flow conduit earlier in the program, resulting in less geophysical surveying, less drilling time and expense, and saved pumping costs by the mining client.

Site characterization programs for karstic aquifers would benefit from the application of the colloidal borescope method and BEERS. The direct measurement of flow velocity and direction information using boreholes helps us to understand the preferential karstic flow pathways, and whether the directions of groundwater flow through these karstic pathways differ substantially from averaging techniques for prediction of aquifer flow direction and discharge rate. Specifically, the testing can be used to detect offsite conduit flow that is by-passing a pump-and-treat remediation system.

Three different applications of the brine enhanced electrical resistivity survey method have been completed, and one of the surveys is presented in this paper. The results of these surveys clearly demonstrate that enhancing the electrical conductivity of conduit flow in a karstified bedrock aquifer will create a strong geophysical anomaly which can be detected to depths of at least $91 \mathrm{~m}(300 \mathrm{ft})$ and possibly deeper. The method provides a rapid and cost-effective tool for remedial-locating of water flow pathways during the early period of a flooding crisis for a mine owner, or a leakage crisis for a dam operator. If designed and implemented properly, the exploration time leading up to grouting repair of the flooding pathway, can be shortened to several weeks from several months, which should translate into substantial cost savings. 


\section{Recommendations}

The application of the colloidal borescope system would benefit from additional setup time for the borescope to minimize edge effects, which is a software operational issue. The borescope should be positioned within the conduit flow to avoid particle swirling action, which will require additional time and prior knowledge of exact depths of karst conduits through other borehole logs. Elevated turbidity levels in the test interval can overwhelm the borescope particle tracking software, therefore the method would benefit from some turbidity screening prior to test startup. For testing of karst for horizontal flow direction and rate, the method seems to produce good data, provided that the test duration is long enough to overcome swirling action in the borehole, and the borescope is placed into the void and away from the wall or clay-fill material, and a large population of particles is tracked. The placement of the borescope should be guided by geologic logs and optical televiewer $\operatorname{logs}$, as available. A test duration of 1 to 2 hours seems appropriate.

\section{Acknowledgments}

The development of the BEERS geophysical approach would not have been possible without the tireless assistance of Mr. Jim Stuby, Senior Geophysicist, with Earth Resources Technology, Inc., who organized and managed the data collection, and who provided data processing design and implementation, and who contributed to the data interpretation.

The author is also grateful to Mr. Peter M. Kearl, formerly of AquaVision Environmental, LLC, who invented and developed the colloidal borescope technology for commercial use, for his peer review of the data collected by the colloidal borescope, and the review of our data interpretations.

\section{References}

Bruce D A. 2004. Keeping water out of the quarry floor, part 1: emergency procedures for dealing with water in heavily karstified limestone deposits. Aggregates Manager, 9 (1): 16-19.

Bruce DA, Traylor RP, Lolcama JL. 2001. The sealing of a massive water flow conduit through karstic limestone. foundations and ground improvement. Proceedings of a specialty conference, American Society of Civil Engineers, Blacksburg, VA, June 9-13, Geotechnical Special Publication No. 113: $160-174$.
Kerfoot WB. 1988. Monitoring well construction and recommended procedures for direct groundwater flow measurements using a heat-pulsing flowmeter. In: Collins AG, Johnson AI, editors. Ground-Water Contamination: Field Methods. American Society for Testing and Materials, Philadelphia, 146-161.

Lolcama JL, Stuby JL. 2015. Case studies in the locating of groundwater flow channels in carbonate aquifers using spontaneous potential, and brine-enhanced electrical resistivity geophysical methods. ASDSO Dam Safety 2015 Conference Proceedings, New Orleans, Louisiana, September 13-17.

Nettles S, Cross E. 2007. Utilizing multi-electrode electrical resistivity to identify karst problems and characterize groundwater systems: an innovative and cost-effective approach. Proceedings of the 4th Conference on Hydrogeology, Ecology, Monitoring, and Management of Ground Water in Karst Terrains; National Groundwater Association, Safety Harbor, FL, Feb. 27-28.

Willowstick Technologies LLC. 2006. Aquatrack ${ }^{\mathrm{TM}}$ uses proven principles to map subsurface water. Open Technology Whitepaper.

Wilson JT, Mandell WA, Paillet FL, Bayless ER, Hanson RT, Kearl PM, Kerfoot WB, Newhouse M, Pedler WH. 2001. An evaluation of borehole flowmeters used to measure horizontal groundwater flow in limestones of Indiana, Kentucky, Tennessee, US Geological Survey WaterResources Investigations Report 01-4139. 
